\title{
Endovascular treatment of wide-neck saccular renal artery aneurysm with waffle-cone technique
}

\section{Tratamento endovascular de aneurisma renal sacular com colo largo com técnica do waffle-cone}

\author{
Paulo Eduardo Ocke Reis' (iD, Guilherme de Palma Abrão', Leonardo Roever² (D)
}

\begin{abstract}
In the past, treatment of visceral artery aneurysms (VAAs) was exclusively surgical. These aneurysms were rarely diagnosed in elective or emergency cases. Development of imaging techniques and endovascular procedures has changed the history of the therapeutic options for this pathology. Endovascular management of VAAs has arisen to advances in endovascular techniques and has achieved high efficacy.
\end{abstract}

Keywords: aneurysm; endovascular; endovascular procedure; therapeutic embolization; stent.

\section{Resumo}

No passado, o tratamento de aneurismas da artéria visceral (VAAs) era exclusivamente cirúrgico e raramente diagnosticado em casos eletivos ou de emergência. O desenvolvimento de técnicas de imagem e procedimentos endovasculares mudou a história das opções terapêuticas dessa patologia. O manejo endovascular de VAAs surgiu devido ao avanço das técnicas endovasculares, o qual apresentou uma alta eficácia.

Palavras-chave: aneurisma; endovascular; procedimento endovascular; stent.

How to cite: Reis PEO, Abrão GP, Roever L. Endovascular treatment of wide-neck saccular renal artery aneurysm with waffle-cone technique. 2021;20:e20200116. https://doi.org/10.1590/1677-5449.200116

1 Universidade Federal Fluminense - UFF, Niterói, RJ, Brasil.

${ }^{2}$ Universidade Federal de Uberlândia - UFU, Uberlândia, MG, Brasil.

Financial support: None.

Conflicts of interest: No conflicts of interest declared concerning the publication of this article.

Ethic protocol: CAAE: 45521821.6 .0000 .5243

Submitted: June 30, 2020. Accepted: October 18, 2020

The study was carried out at Universidade Federal Fluminense (UFF), Niterói, RJ, Brazil. 


\section{INTRODUCTION}

In the past, treatment of visceral artery aneurysms (VAAs) was exclusively surgical, using open approaches, until development of imaging techniques and endovascular devices expanded the treatment options. ${ }^{1,2}$ The key to success is to choose the best technique for each case individually. Almost all patients are asymptomatic and the principal indication for treating VAAs is aneurysm size; 2.0 or $2.5 \mathrm{~cm}$ when not ruptured..$^{1-5}$ These aneurysms are still rare and if they rupture the mortality rate is high, so the objective of treatment is to prevent rupture by excluding the aneurysm sac while saving branch patency. ${ }^{1-6}$ Coil embolization has emerged as a management method for these patients, offering high efficacy and low invasiveness. ${ }^{1-6}$ Techniques for treatment of wide-necked aneurysms using Stent-Assisted Coil Embolization (SACE) have demonstrated effectiveness in complex wide-necked bifurcation cerebral aneurysms and can also be employed in extracranial aneurysms. ${ }^{1-10}$ The goal of treatment is to prevent the aneurysm from expanding by excluding it from the arterial circulation, saving branches and patency and ensuring freedom from rupture or reperfusion. ${ }^{1-6}$ Geometry has been shown to predict need for adjuvant techniques in endovascular treatment of aneurysms. ${ }^{11,12}$ Wide-neck aneurysms aspect and dome-to-neck ratios $<1.2 \mathrm{~mm}$ or neck length $>4.0 \mathrm{~mm}$, almost always require adjuvant techniques in addition to coil embolization, such as stent-assisted techniques or balloon remodeling techniques. ${ }^{1-12}$

\section{PART I - CLINICAL SITUATION}

A 62-year-old woman presented with a saccular renal artery aneurysm. She was asymptomatic and diagnosis was the result of a finding during a regular clinical check-up. She had an intraparenchymal renal saccular aneurysm, measuring $2.7 \times 2.0 \mathrm{~cm}$ and with a large aneurysm neck length ( $>4 \mathrm{~mm}$ ), which would need a remodeling technique to exclude the aneurysm sac (Figure 1).

\section{PART II - WHAT WAS DONE}

Our treatment approach was SACE using a wafflecone technique $\mathrm{e}^{1-10}$ (Figure 1). Access was obtained, the right common femoral artery was punctured using the Seldinger technique, and a 6Fr sheath was positioned in the left renal artery. A Prowler Select Plus $^{\circledR}$ microcatheter was then positioned inside the aneurysm and a $4.5 \times 27 \mathrm{~mm}$ Enterprise $^{\circledR}$ (Cordis, Miami, FL, USA) self-expandable stent was implanted into the aneurysm, intentionally covering the bifurcation.
Using a coaxial technique, a Prowler ${ }^{\circledR}$ microcatheter was advanced into the aneurysm through the stent lumen for coiling (Figure 2). A total of 12 Trufill DCS Orbit coils ${ }^{\circledR}$ were then deployed by controlled release. Digital subtraction angiography demonstrated complete occlusion of the aneurysm after stent assisted coiling (Figures 3 and 4).

Final control arteriography demonstrated the aneurysm completely occluded (Figure 5). Control CT showed successful exclusion of a $2.7 \times 2.0 \mathrm{~cm}$ saccular intraparenchymal renal aneurysm (Figure 6). The patient was given dual antiplatelet therapy after the procedure. She gave her consent to publication of her case details and images.

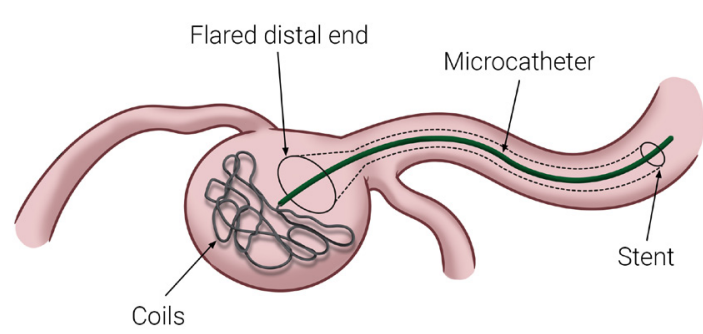

Figure 1. Schematic diagram illustrating a wide-necked saccular aneurysm treated with a Waffle-Cone Technique. Modified from Khattak et al. ${ }^{11}$

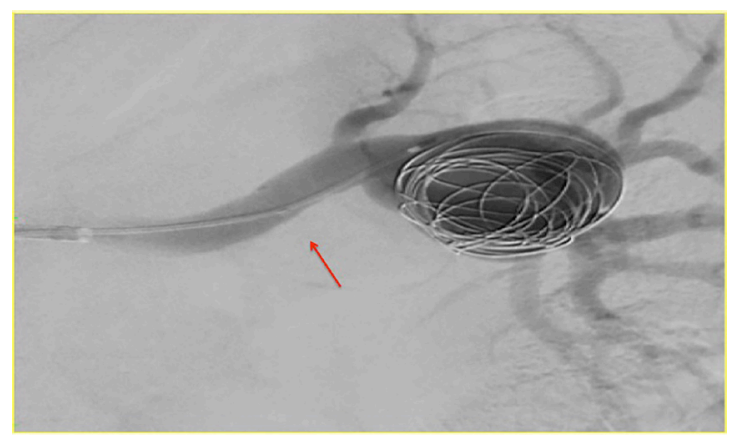

Figure 2. Microcatheter positioned inside the aneurysm sac, so we deployed the micro coils. Stent already deployed (red arrow).

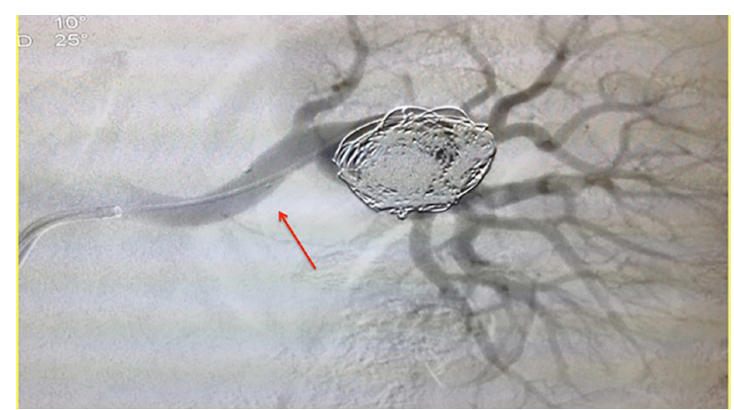

Figure 3. Final control arteriography. The red arrow indicates the radiopaque marking on the stent. 


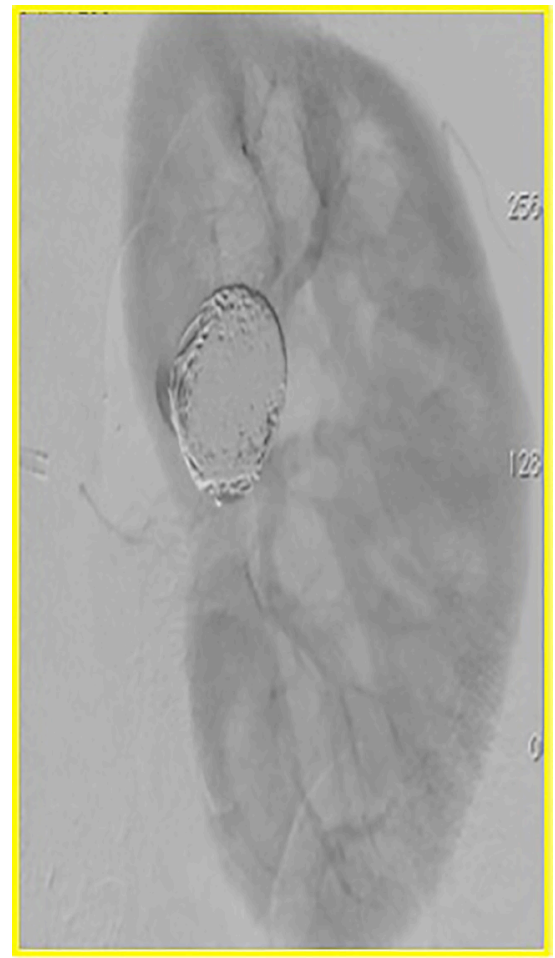

Figure 4. Late phase control arteriography showing complete exclusion of the aneurysm.

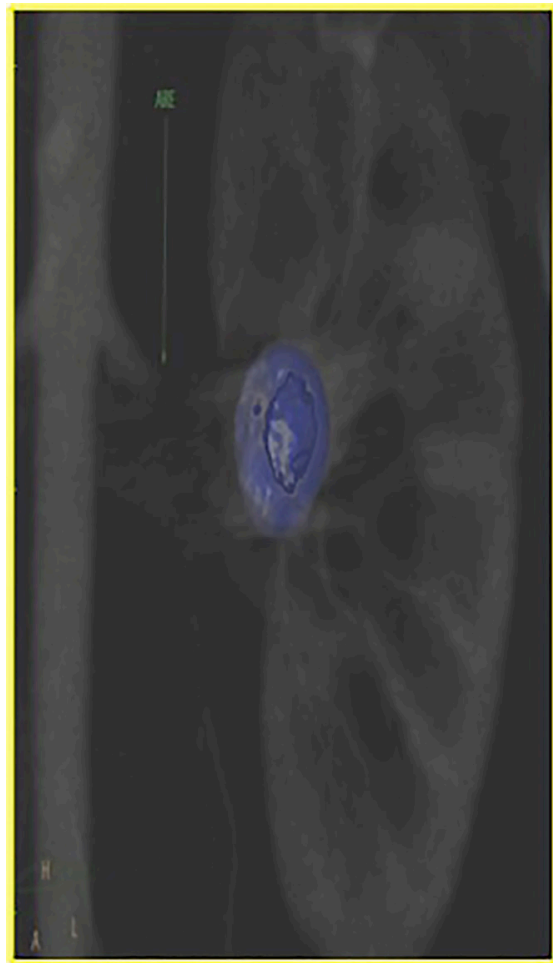

Figure 5. Coronal angiotomography with an algorithm to reduce metallic artifacts showing successful exclusion of an intraparenchymal renal saccular aneurysm. ARE = renal artery.

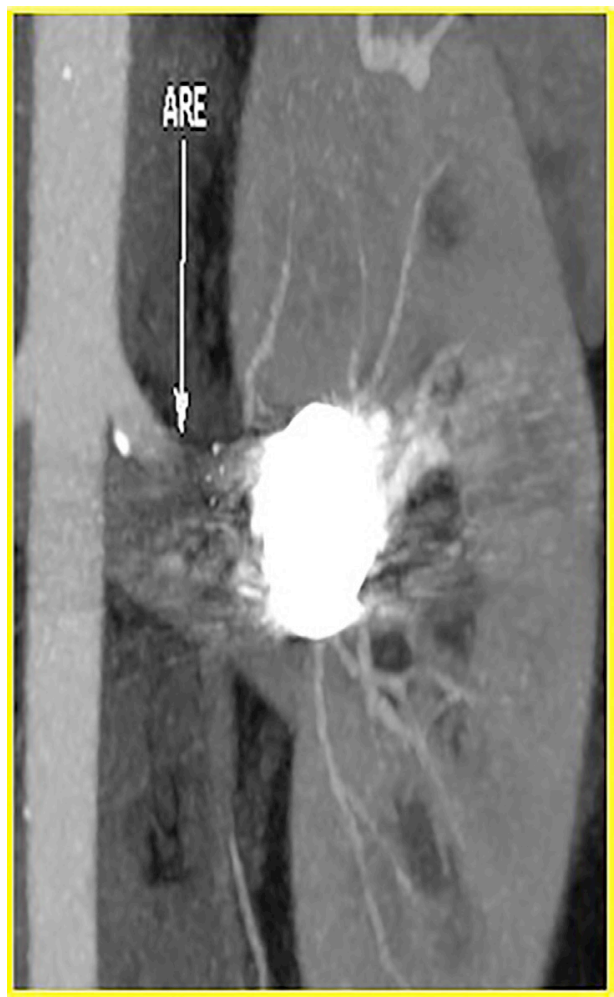

Figure 6. Coronal reconstruction of angiotomography with an algorithm to reduce metallic artifacts, showing complete exclusion of a $2.7 \times 2.0 \mathrm{~mm}$ aneurysm sac using stent-assisted coil embolization. ARE = renal artery.

\section{DISCUSSION}

Several stent-supported coiling techniques have been used to treat wide-necked bifurcation aneurysms, including waffle-cone constructs. ${ }^{2-5}$ First conceived in neuro-interventional practice, the differentiating factor with this technique is that it uses the stent as support to guide positioning of the coils to prevent prolapse during deployment and to help packing, resulting in a stable scaffold jailing the coils in the aneurysm sac. ${ }^{2-8}$ The diameter of the nitinol stent is determined based on assessment of the size of the aneurysm neck and the diameter of the proximal parent artery. The wafflecone is thus created by deploying the stent's proximal end within the renal artery and the distal end at the proximal extreme of the aneurysm. This placement avoids migration of the coils and allows good flow through the division branches. Liu showed that the waffle cone technique is an effective alternative tool for stent-assisted coiling of complex, wide-necked bifurcation aneurysms with unfavorable anatomies. ${ }^{7}$ Authors have determined criteria to define an approach to difficult aneurysms with aspect and dome-to-neck ratio $<1.2 \mathrm{~mm}$, and a neck width $>4.0 \mathrm{~mm} .{ }^{10}$ In our decision, the ratio measurement determined during 
preoperative planning was the independent predictor for an adjuvant technique.

In conclusion, endovascular treatment of VAAs with stent-assisted coiling is a viable and safe procedure that is effective for treating complex wide-necked bifurcation renal artery aneurysms whose anatomic features are unfavorable for conventional coiling. ${ }^{1-5}$ The Waffle-Cone technique seems to be a technical option with effective arterial remodeling. However, long-term follow-up results are needed for evaluation.

\section{REFERENCES}

1. Tulsyan N, Kashyap VS, Greenberg RK, et al. The endovascular management of visceral artery aneurysms and pseudoaneurysms. J Vasc Surg. 2007;45(2):276-83, discussion 283. http://dx.doi. org/10.1016/j.jvs.2006.10.049. PMid:17264002.

2. Piotin $M, B$ lanc $R$, Spelle $L$, et al. Stent-assisted coiling of intracranial aneurysms: clinical and angiographic results in 216 consecutive aneurysms. Stroke. 2010;41(1):110-5. http://dx.doi.org/10.1161/ STROKEAHA.109.558114. PMid:19959540.

3. Rahal JP, Dandamudi VS, Safain MG, Malek AM. Double waffle-cone technique using twin Solitaire detachable stents for treatment of an ultra-wide necked aneurysm. J Clin Neurosci. 2014;21(6):101923. http://dx.doi.org/10.1016/j.jocn.2013.08.029. PMid:24412295.

4. Garg N, Pipinos II, Longo GM, Thorell WE, Lynch TG, Johanning JM. Detachable coils for repair of extra parenchymal renal artery aneurysms: an alternative to surgical therapy. Ann Vasc Surg. 2007;21(1):97-110. http://dx.doi.org/10.1016/j.avsg.2006.10.007. PMid:17349346.

5. Rossi M, Varano GM, Orgera G, Rebonato A, Laurino F, De Nunzio C. Wide-neck renal artery aneurysm: parenchymal sparing endovascular treatment with a new device. BMC Urol. 2014;14:42. http://dx.doi.org/10.1186/1471-2490-14-42. PMid:24885940.

6. Chaer RA, Abularrage C), Coleman DM, et al. The Society for Vascular Surgery clinical practice guidelines on the management of visceral aneurysms. J Vasc Surg. 2020;72(1S):3S-39S. http:// dx.doi.org/10.1016/j.jvs.2020.01.039. PMid:32201007.

7. Reis PEO, Roever L, Reis IFO. Embolization for visceral artery aneurisms: what's your opinion? J Vasc Endovasc Surg. 2016;1:1. http://dx.doi.org/10.21767/2573-4482.100001.

8. Liu W, Kung DK, Policeni B, Rossen JD, Jabbour PM, Hasan DM. Stent-assisted coil embolization of complex wide-necked bifurcation cerebral aneurysms using the "Waffle Cone" technique a review of ten consecutive cases. Interv Neuroradiol. 2012;18(1):20-8. http:// dx.doi.org/10.1177/159101991201800103. PMid:22440597.

9. Luo CB, Wei C), Chang FC, Teng MM, Lirng JF, Chang CY. Stentassisted embolization of internal carotid artery aneurysms. J Chin Med Assoc. 2003;66(8):460-6. PMid:14604309.

10. Clark TW, Sankin A, Becske T, Nelson PK, Fox M. Stent-assisted gugliemi detachable coil repair of wide-necked renal artery aneurysm using 3-D angiography. Vasc Endovascular Surg. 2007;41(6):528-32. http://dx.doi.org/10.1177/1538574407305021. PMid:18166635.

11. Khattak YJ, Sibaie AA, Anwar M, Sayani R. Stents and stent mimickers in endovascular management of wide-neck intracranial aneurysms. Cureus. 2018;10(10):e3420. http://dx.doi.org/10.7759/ cureus.3420. PMid:30542634.

12. Brinjikji W, Cloft HJ, Kallmes DF. Difficult aneurysms for endovascular treatment: overwide or undertall? AJNR Am J Neuroradiol. 2009;30(8):1513-7. http://dx.doi.org/10.3174/ajnr. A1633. PMid:19461057.

Correspondence Paulo Eduardo Ocke Reis Universidade Federal Fluminense - UFF, Hospital Universitário Antonio Pedro, Departamento de Cirurgia Geral e Especializada Rua Marquês do Paraná, 303 - Centro CEP 24033-900 - Niterói (RJ), Brasil Tel.: +55 (21) 2629-5000 E-mail: ockereis@yahoo.com

Author information

PEOR - Specialist in vascular and endovascular surgery; Adjunct professor of vascular surgery, Universidade Federal Fluminense (UFF). GPA - Specialist in interventional neuroradiology; Adjunct professor of radiology, Universidade Federal Fluminense (UFF).

LR - Centro de Pesquisa Clínica, Universidade Federal de Uberlândia (UFU).

Author contributions Conception and design: PEOR, GPA, LR Analysis and interpretation: PEOR, GPA, LR Data collection: PEOR, GPA, LR Writing the article: PEOR, GPA, LR Critical revision of the article: PEOR, GPA Final approval of the article*: PEOR, GPA, LR Statistical analysis: GPA, LR Overall responsibility: PEOR, GPA, LR

*All authors have read and approved of the final version of the article submitted to I Vasc Bras. 